\title{
Perceptions of Teachers and Head Teachers on the Effectiveness of Inclusive Education in Public Primary Schools in Yatta Division Machakos County
}

\author{
Mutungi N. Peter \\ Mount Kenya University, School of Education \\ Email: petermutungi12@gmail.com \\ Moses Nene Nderitu \\ Mount Kenya University, School of Education \\ Email: chemichemis2012@rocketmail.com
}

\section{Doi:10.5901/jesr.2014.v4n1p91}

\section{Abstract}

\begin{abstract}
The trends in the educational provision for children with disabilities have since the past two and a half decades continued to focus on their education in the same setting as that for their peers without special needs. The education now being most advocated for children with disability is inclusive education. Despite the many benefits of inclusion, difficulties inherent in this process are major setbacks to wider implementation of inclusive education. Many teachers of regular schools and other stakeholders doubt the workability of the strategy and resist the idea of having children with special needs in regular classrooms. Teachers play a critical role in the workability and effectiveness of inclusive education. However, many at times they are faced by different tasking challenges and that make inclusive education difficult to implement. These challenges are important to understand so that new methods can be implemented to improve the educational situation in the field of special needs education particularly inclusive learning. The study aimed to establish the perceptions of headteachers and teachers on the implementation of inclusive education, in Yatta Division, Machakos County.
\end{abstract}

Keywords: Education, Strategies, Learners Inclusive Education, Schools

\section{Background of the Study}

According to Bailey (1998), Inclusive education refers to an education system which constantly works on increasing participation and removing exclusion from all the aspects of schooling, in a way which makes a student feel no different from any other student and which ensures achievement. Inclusive education was first introduced from an international perspective at the Salamanca World Conference in 1994 in Spain which included international papers on special needs children (Ainscow \& Cesar, 2006). In developing countries, inclusive education is seen as an approach to serve special educational needs children within general education settings. However, internationally, inclusive education is seen as a system which caters for the needs of a diverse range of learners and supports diversity, effectively eliminating all forms of discrimination (UNESCO, 2009). Education is the right of all children, and inclusive education aims to ensure that all children have access to an appropriate, relevant, affordable and effective education within their community.

Most conceptual literature on inclusive education was Northern (European and North American) in origin, taking a 'whole-school' approach to institutional change (Peters, 2004), and influenced by the social model of disability. Children in special schools were seen as geographically and socially segregated from their peers, and the initial movement to integrate these students in mainstream schools ('integration') shifted to one where the whole school was encouraged to become more adaptable and inclusive in its day-to-day educational practices for all students ('inclusive education'). Pedagogy in particular was highlighted as the key to meeting all students' educational needs by making the curriculum flexible, and so more accessible. By recognizing that teaching methods which can make curriculum accessible to children with disabilities can also make learning accessible to all students (Ainscow, 2005), a teacher or school principal is well on the way to improving the overall quality of their school. In this way, inclusive education is not a disability-only issue, but an educational quality issue.

According to a recent report published by the World Health Organisation (WHO), 15\% of the global populations (200 million) suffer from some form of disability (The Daily eProthom Alo, 2011). Some of them are children, women or 
aged persons with disabilities. Charema (2007) claims that, $87 \%$ of individuals with disabilities in developing countries live in rural areas. Inclusive education is considered to be a means of providing educational opportunities for all children, including children with disabilities. This means placing children with physical disabilities, behavioral or academic difficulties or social concerns together with regular children in mainstream classrooms (Wilczenski, 1992).

Special needs education started in Kenya after the end of the Second World War and has since been mainly offered to four categories of children with disabilities, namely; children with hearing impairments, mental handicaps, visual impairments and those with physical handicaps (GoK 2008). Education to these children was only offered in special schools until the 1970s when units and integrated programmes were initiated. However, Educational opportunities for children (learners) with special needs and disabilities are a major challenge to the education sector. The national education system has been characterized by lack of systems and facilities that respond to the challenges faced by learners with special needs.

The government is placing emphasis on inclusive education through regular schools for SNE learners as opposed to the practice of strictly using special schools and special units attached to regular schools. However, Special schools and units are essential for learners with special needs in the areas of hearing, visual, mental and serious physical challenges. With the increase in demand for special needs education and in line with the international development, the government has adopted Inclusive Education (GoK 2008). This approach will increase access to education for children with special needs. Inclusive education calls for restructuring of the education system in terms of physical facilities, curriculum, instruction and other aspects to children joining schools of their choice and convenience. It is important to note that government will face serious challenges in providing education to all its citizens with special needs in education unless it implements inclusive education. The government under the FPE programme is facilitating provision of additional capitation grants to facilitate implementation of inclusive education. The funds are provided to learners with special needs enrolled in both special education institutions and units attached to regular schools.

So far, majority of learners with special needs and disabilities in Kenya do not access educational services. For instance, in 1999 there were only 22,000 learners with special needs and disabilities enrolled in special schools, units and integrated programmes. This number rose to 26,885 in 2003 (Koech Report, 1999). This compares poorly with proportion in general education. Currently, there are over 1100 units and 100 public special schools in the country which include vocational and technical institutions that cater for learners with special needs and disabilities (MoE 2008). In view of the above, this situation calls for a re-appraisal of available approaches to expand Special Needs Education services so as to achieve an enrolment rate at par with that of other children. To attain this, Kenyan Government needs to ensure the realization of inclusive education and simultaneously develop and implement guidelines that mainstream special needs education at all levels of the education system. 


\section{The conceptual Framework}

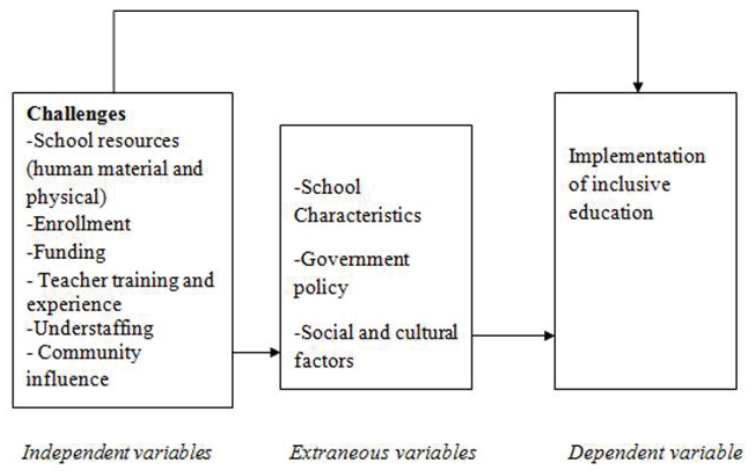

The movement towards inclusive education for children with special needs began in the 1960s (Foreman, 2005). The United Nations (UN) has made a number of influential declarations regarding inclusive education, such as the Convention against Discrimination in Education (1960), the Declaration on the Rights of Disabled Persons (1975), and the Convention on the Rights of the Child (1989). In 1990, the World Conference on Education for All was held in Jomtien, Thailand. A further conference in 2000 in Senegal gave rise to the Dakar framework for Education for All, in which the international community pledged to ensure education as a right for all people, irrespective of individual differences. Subsequently in 1994, inclusive education was put forward as a concept at the Salamanca World Conference on Special Needs Education in Spain. The Salamanca statement is arguably the most significant international document in the field of special education (Ainscow \& Cesar, 2006). In the Salamanca statement, inclusive education is described as a framework for action that would accommodate all children "regardless of their physical, intellectual, social, emotional, linguistic or other conditions" (Salamanca Statement and Framework for Action, UNESCO, 1994, Article 3). This includes disadvantaged or marginalized children such as street and working children from remote or nomadic populations, children from linguistic, ethnic or cultural minorities, and children with special educational needs and disabilities. The statement argues that regular schools with an inclusive setting are the most effective way to fight against discriminatory attitudes in order to build an inclusive society and to achieve education for all (UNESCO, 1994).

Essentially, the Salamanca Conference on Special Needs Education gave approval to the notion of inclusive education (Ainscow \& Cesar, 2006). The UNESCO International Conference in Education was held in Geneva in 2008 and the focus of this conference was the inclusion of a more diverse range of learners, regardless of ability or characteristics, as well as the promotion of respect for the needs and abilities of learners and the elimination all forms of discrimination (UNESCO, 2009).

During the subsequent years, there have been considerable efforts in many countries to affect educational policy and practice towards inclusive education as is appropriate for that country (Ainscow \& Cesar, 2006). The appropriateness of separate school systems has been challenged from a human rights point of view (Ainscow, Booth, Dyson, Farell, Frankham, Gallannaugh, Howes \& Smith , 2006). In order to ensure education for all, including those children who have disabilities, it is increasingly asserted that modifying ordinary schools is the most effective way of doing this (Sebba \& Sachdev, 1997). Thus, integrated programmes take the form of special classes within ordinary schools. A problem reported by many countries that have national policies regarding integration is that there is evidence of a significant increase in the proportions of pupils being categorized as disabled as a way to earn additional resources for the schools (Booth \& Ainscow, 1998).

\section{Inclusive Education in Developing Countries}

The majority of the world's population of children with disabilities lives in developing countries. Out of a world population approximately 150 million live in Africa, Asia, Latin America, the Caribbean and the Middle East (Eleweke \& Rodda, 2002). Despite international declarations regarding the implementation of inclusive education, there are challenges in 
both developed and developing countries, such as gaps between policies and practices, negative attitudes towards inclusion, and lack of sufficient funding (Charema, 2007).

In the Indian context "inclusive education is rapidly becoming a part of official rhetoric" (Singal, 2008).There are approximately 55 million children who are already excluded from the mainstream education system owing to their geographical isolation, social class, religion and different categories of ethnic group based exclusion (Mitchell, 2008). At the same time, the Government of Uganda is now placing children with disabilities (such as hearing disabilities) in inclusive school settings. Another developing country, Costa-Rica, is also developing inclusion with different educational service models such as consulting teachers, educational assistance teams, joining teams and resource centres, though they have little publication in this field (Stough, 2003).

It is suggested by the various researchers that developing countries also need some changes in their policies to implement inclusive education. For instance, Singal (2008) points out that, in India, in order to bring about the successful implementation of inclusive education, it is necessary to motivate people for their support, to change classroom practices and implement some pedagogical rather than structural changes. Similarly, Kristensen, Onen \& Loican (2003) argue that developing countries such as Uganda, are facing similar challenges in the implementation of inclusive education. It is suggested that they also need some support regarding the scarcity of teaching materials, extensive diversity, negative attitudes and large class.

\section{Practicing Inclusive Education}

Stakes and Hornby (2000) suggest that teachers have to identify, possibly through assessment individual children's learning style in order to meet their needs .By learning style, it is meant the application of an individual's cognitive style to a learning situation (Mortimer, 2000, cited in Exley, 2003), the nature of the learning environment and the structure of a lesson (Chinn, 2001). Cognitive style is concerned with an individual's characteristic and relatively consistent way of processing incoming information of all types from the environment. The argument is predicated on the premise that since each person is different, 'the way he learns will also differ' (Exley, 2003). Will that mean the teacher has to teach to satisfy the learning style of the different ranges of students in the class. This may be impossible considering the huge numbers of class sizes that some schools particularly in countries such as Ghana have to deal with (Gyimah, 2006).

Norwich and Lewis's (2001) found out that there is no Special Needs Education specific pedagogy. On the other hand, there is a form of generic teaching which assume that 'what works with most pupils also work for all pupils' (Norwich and Lewis). Though some differences may seem to exist, for instance, in the approaches used in teaching children with autism compared with children with specific language impairments, Florian and Davis (2004) found that the 'teaching approaches and strategies themselves were not sufficiently differentiated from those that are used to teach all children to justify categorization as specialist pedagogy'. This view, not withstanding, Florian (2008) recognizes that what works for most children does not work with some. It will therefore mean that if we want all children to access the school curriculum and succeed academically, some form of differentiation will be required.

\section{Teachers' Perceptions on Implementation of Inclusive Education}

Although the movement for inclusive education is part of a broad human rights agenda, many educators have serious reservations about supporting the widespread placement of pupils with special educational needs (Florien, 1998). Bowman (1986), in her fourteen nation UNSESCO study of approximately 1000 teachers' with experience of teaching children with special educational needs, reported a wide range of difference in teacher opinions regarding integration. The teachers were found to favour different types of children for integration into ordinary classes.

Leyser, Kapperman and Keller (1994) undertook a cross-cultural a cross study of teacher attitudes towards inclusion or integration in the United States, Germany, Israel, Ghana, Taiwan and the Philippines. Their findings showed that there were differences in attitude to inclusion between these countries. Teachers in the United States and in Germany had the most positive attitudes. Positive attitudes in the United States were attributed to inclusion being widely practiced there as a result of Public Law. Teachers in Germany exhibited positive attitudes to inclusion, though at the time of the study, Germany had no special education legislation, their teachers were not provided with special education training, their children eighth special educational needs were educated in segregated settings, and integration was being practiced only on an experimental basis. Teacher attitudes were less positive in Ghana, the Philippines, Israel and Taiwan. The authors reasoned that this could probably be due to limited or nonexistent training for teachers to acquire integration competencies. Also, there were very few opportunities for integration in these countries. 
Singal (2006) concluded that many teachers believe that children who need academic moderation would be unable to cope with the level of academic demand in the mainstream schooling system. She argued that such children should be taught in a separate system of segregated education. She also noted that inclusion programs are not fruitful for the average teacher or child. There is a negative correlation between students" academic ability and their level of disability such as dyslexia or autism (Slavin, 2011). However, from a comparative study in inclusive and separate settings, the Canadian Council on Learning (2009) found that there was a favorable academic outcome for students with special education needs educated in inclusive settings.

From the range of studies discussed here, most reported that teachers possess positive attitudes or views on inclusive education (Ali, Mustapha \& Jelas, 2006). If teachers have positive views on inclusion, then they value all children, whatever their needs, and interact with them accordingly (Whyte, 2005). Ali, Mustapha and Jelas (2006) used a self-rated questionnaire with teachers in Malaysia to measure teacher attitude. Their findings were that overall teachers had positive attitudes towards inclusive education and agreed that inclusive education intensifies social interaction, while it decreases negative stereotypes of special educational needs children. The authors argued for cooperation between mainstream and special education teachers in order to implement inclusive education. Loreman, Forlin \& Sharma (2007) in their study compared four countries" teacher attitudes, using a questionnaire and found that teachers are positive towards inclusive education for children with special needs, mainly with social, emotional and behavioral disabilities.

Ross-Hill (2009) shared the same view after examining the different attitudes of elementary and secondary school teachers towards inclusion, and how best to develop an inclusive environment based on these attitudes. The results indicated that most teachers either supported inclusion practices in regular classrooms or did not have strong views on inclusive education. Croll and Moses (2000) investigated teachers" views on inclusive education and found that nine out of ten teachers thought that the regular classroom was the right place for children with disabilities. They suggested that pre-existing teacher attitudes and views are fundamental to their resulting implementation and experiences of inclusive education.

The physical placement alone of students with special need into regular school does not solve the problems. No matter the inclusion is supported by the professional and parents, consideration of all viewpoints are crucial. Before implementing the inclusive education, it should be agreed by most teachers in school, especially who would teach the classes. Without the considerations of teachers' thoughts, decisions made are not validated. Teachers may think that the small class teaching can enhance the efficiency and effectiveness of students' learning, although there are students with special needs should be paid more attention to. But, the utmost importance is that teachers can tackle the learning problem of the developmentally challenged students and handle the atmosphere of the class in appropriate manner. Teachers without training may lose control that they do not know how could handle the situation. Teachers could take back control of his class by not being the centre of all classroom routines. More interaction between students and teacher are necessary for quality education. It is easier for teachers to know the students' progress and then adjust the teaching speed.

\section{Challenges Facing Implementation of Inclusive Education}

The accommodation of a wide range of students in the same classroom gives rise to many challenges. Simple teaching resources that could normally be produced locally, such as maps, charts and other illustrative devices are not available in many educational institutions in developing countries (Eleweke \& Rodda, 2002). The lack of facilities and teaching materials are major impediments to the implementation of inclusive education.

To implement inclusive education in classrooms, it is important that teachers provide an effective and stimulating educational environment for all pupils. In addition, teachers" experience and their training significantly influence their attitudes (Meng, 2008). Despite the fact that it is essential to staff inclusive classes with skilled and trained teachers, there is a shortage of inclusive teacher training programmes. This is a major problem to be solved if the quota of trained teachers is to be met (Hossain, 2004; Kibria, 2005). Research indicates that adequately trained professionals are required for students with special needs (Eleweke \& Rodda, 2002). In addition, support personnel for training programmes such as audiologists, psychologists, speech and language pathologists, communication support workers and interpreters are very scarce in many developing countries (Eleweke \& Rodda, 2002).

Teachers' existing knowledge is not always sufficient for inclusive teaching. Many teachers have claimed that inclusion policies forced them to enter areas they were unsure about or not interested in (Ali, Mustapha \& Jelas, 2006). On the other hand, the appropriate educational background of teachers does have a positive impact on inclusive teaching (Meng, 2008). 
Research has clearly revealed that teaching is increasingly becoming more diversified, their workloads are blooming and many regular-class teachers are not enthusiastic to engage in whole inclusion education. The major concerns of teachers are the perceived threat to their own competency and the anticipated misbehavior of students with special needs. Teachers teach the class in a short time span with little time for reflection and debate. It is a drastic change to teachers' existing way of life.

Moreover, teachers may think that the students with special need may hinder the progress of the whole regular class that the normal student cannot retain the education who are able to handle. They may merely focus on the specially needed students' works but ignored other student who only did the works on their own. These might lower the progress of a typical student should learn. Not only does the learning atmosphere is important to teaching, but also the standard of assessment to students. Whether the same level of assessment given to the typical students and specially needed students is controversial, because it greatly affects the reveal in terms of the knowledge of students, and their further studies. In addition, the students may have disciplinary problem and could not concentrate on their studies. Despite the fact that teachers have several years of teaching experience and have received education in teaching, only few are trained to teach inclusive education and could handle the real situation. The needs of teachers and school should be addressed so that both sides would not become too stressed to participate in inclusion education.

\section{Research Methodology}

This study employed descriptive survey research design. Descriptive survey research designs are used in preliminary and exploratory studies to allow researchers to gather information, summarize, present and interpret for the purpose of clarification (Orodho, 2002). Mugenda and Mugenda (1999) on the other hand give the purpose of descriptive research as determining and reporting the way things are. The study fits within the provisions of descriptive survey research design because the researcher was to collect data and report the way things are without manipulating any variables.

The study utilized two sets of data collection instruments which were questionnaires and interview schedule. The questionnaires were used for data collection because as Gay (1992) argues that questionnaires give respondents freedom to express their views or opinion and also to make suggestions. The interview schedule created a context where the participant spoke freely and openly by utilizing communication techniques such as clarification, paraphrasing, and summarizing, probing and minimal verbal as well as non-verbal responses. During the interview the researcher used bracketing (putting preconceived ideas aside) and intuiting. The interview was conducted until data was saturated as determined by the interview guide.

After collecting the data, the researcher conducted data cleaning, which involves identification of incomplete or inaccurate responses, which were corrected to improve the quality of the responses. This research yielded data that required both qualitative and quantitative analysis. Quantitative analysis entails analyzing numbers about a situation by choosing specific aspects of that situation. Descriptive statistics was used to analyze the quantitative data obtained. The statistics used included frequency counts, means and percentages. Quantitative data analysis required the use of Statistical Package for Social Sciences (SPSS) version 17. As Martin and Acuna (2002) observe, SPSS is able to handle large amount of data, and given its wide spectrum of statistical procedures purposefully designed for social sciences, it is also quite efficient. On the other hand, qualitative analysis entails analyzing in words or pictures by collecting data, recording peoples' experiences not selecting any pre-chosen aspect. The qualitative data obtained in this study were analyzed by organizing it into similar themes and tallying the number of similar responses. The results of data analysis were presented using frequency distribution tables, bar graphs and pie charts.

\section{Data Analysis, Presentation and Interpretation}

The findings of this study are presented thematically with the themes developed from the research questions as follows.

\subsection{Response Rate}

The study administered the research instruments to the subjects and the response rate is shown by the data on Table 2 .

Table 2: Response Rate

\begin{tabular}{|c|c|c|c|c|c|}
\hline \multirow[t]{2}{*}{ Instrument Category } & \multicolumn{2}{|c|}{ Response } & \multicolumn{2}{|c|}{ Non Response } & \\
\hline & Frequency & $\%$ & Frequency & $\%$ & Total \\
\hline
\end{tabular}


Source: Author $2 \overline{2012}$

\begin{tabular}{cccccc} 
Questionnaires & 80 & 88.9 & 10 & 11.1 & 100 \\
Interview & 16 & 88.9 & 2 & 11.1 & 100 \\
Total & 96 & 88.9 & 2 & 11.1 & 100 \\
\hline
\end{tabular}

Data on Table 2 indicates that the research was popular in that $96(88.9 \%)$ of the respondents returned the questionnaires. Therefore $88.9 \%$ was a good response and quite representative. The data further reveals that $16(88.9 \%)$ subjects were available and interviewed.

\subsection{Description of the Population}

The study involved 96 subjects that comprised head teachers of public primary schools and teachers in public primary schools.

\subsection{Demographic Data of Respondents}

The demographic profile provides information about the population structure, and helps create a mental picture of the subgroups that exist in the overall population. Researchers obtain demographic information from the study subjects to understand sample characteristics and to determine if samples are representative of the populations of interest (Kirton, 2000). Although demographic variables cannot be manipulated, researchers can explain relationships between them and dependent variables. In this study, the researcher investigated the respondent's characteristics by establishing their gender, age, academic qualification and experience (length of service).

\subsection{Gender of the Respondents}

The study sought to establish how the sample population was distributed by gender, and enable tabulation of responses in this light. Table 3 data reveals how the study subjects were distributed by gender.

Table 3: Gender Distribution of Respondents

\begin{tabular}{lccccc}
\hline \multicolumn{1}{c}{ Category of respondent } & Male & \multicolumn{2}{c}{ Female } \\
& Frequency & $\%$ & Frequency & $\%$ & Total \\
\hline Heat teachers & 12 & 75 & 4 & 25 & 100 \\
Teachers & 43 & 53.8 & 37 & 46.3 & 100 \\
Total & 55 & 57.3 & 41 & 42.7 & 100 \\
\hline
\end{tabular}

Source: Author 2012

According to the findings in Table 3, majority (75\%) headteachers were male and $(25 \%)$ were female, showing that majority schools were headed by male head teachers. Female assistant teachers formed the majority (46.3\%) while (53.8\%) were males. This shows that there is a gender disparity in favour of males in the general composition of Headteachers and teachers. The conclusions that can be drawn from this data is that majority (57.3\%) of the respondents were males compared to $42.7 \%$ females. The data above is further illustrated in the graph below.

Figure 2. Gender Distribution of Respondents

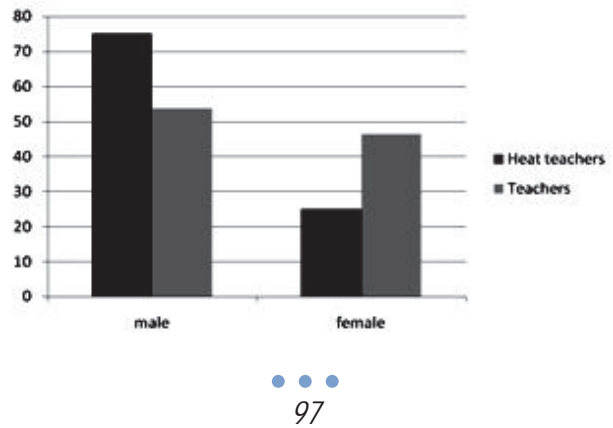




\subsection{Age}

The demographic attribute of age has importance through linkages with individual experience and personal accumulated knowledge. Long-term experience may have influence an influence to effective management. The study sought to establish the age distribution of respondents and the results are shown below

Table 4. Age Distribution of Respondents

\begin{tabular}{ccccc}
\hline Age Interval & Teachers & \multicolumn{2}{c}{ Headteachers } \\
& Frequency & $\%$ & Frequency & $\%$ \\
\hline Below 20 & 2 & 2.5 & 0 & \\
$21-30$ & 12 & 15 & 0 & 0 \\
$31-40$ & 35 & 43.8 & 1 & 6.2 \\
$41-50$ & 25 & 31.3 & 11 & 68.8 \\
Over 51 years & 6 & 7.5 & 4 & 25 \\
Total & 80 & 100 & 28 & 100 \\
\hline
\end{tabular}

Source: Author 2012

The study established that the majority (68.8\%) of the headteachers were in the age bracket of $41-50$ years while the minority $(6.2 \%)$ were in the age $31-40$ years. The study further established that the majority (43.8\%) teachers were aged between ages $31-40$ years, (31.5\%) were aged $41-50$ years while the minority $(2.5 \%)$ were aged below 20 years. The above data is illustrated in the graph below

Figure 3. Age Distribution of Respondents

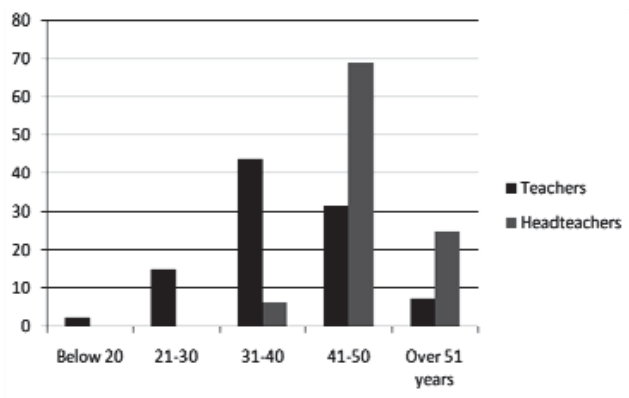

\subsection{Academic Qualification}

The study sought to establish the academic qualification of headteachers and teachers and the data on Table 5 reveals the findings

Table 5: Teachers' Academic Qualification

\begin{tabular}{ccccc}
\hline \multirow{2}{*}{ Qualification } & \multicolumn{2}{c}{ Head Teachers } & \multicolumn{2}{c}{ Teachers } \\
& Frequency & $\%$ & Frequency & $\%$ \\
\hline Certificate & 5 & 31.3 & 28 & 35 \\
Diploma & 8 & 50 & 40 & 50 \\
Bachelors degree & 3 & 18.7 & 6 & 15 \\
Masters & 0 & 0 & 0 & 0 \\
Total & 16 & 100 & 80 & 100
\end{tabular}

Source: Author 2012

The study findings in Table 5 established that the majority 50\% teachers had a diploma qualification while 35\% had certificate qualification while $15 \%$ had bachelor's degree. Headteachers holding diploma qualification accounted for 50\% 
while the rest $31.3 \%$ had certificate, while $18 \%$ had a bachelor's degree qualification. The above data is illustrated in the graph below

Figure 4. Teachers' Academic Qualification

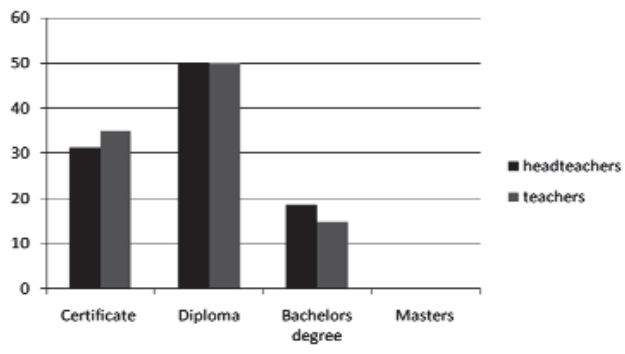

\subsection{Years of Service}

Increased tenure in an organization is positively related to effectiveness, and performance (Mahoney, 1988). The study sought to establish the length of service of the respondents and the results are shown on Table 6

Table 6. Teachers Years of Service

\begin{tabular}{ccccc}
\hline \multirow{2}{*}{ Years of service } & \multicolumn{2}{c}{ Head Teacher } & \multicolumn{2}{c}{ Teachers } \\
& Frequency & $\%$ & Frequency & $\%$ \\
\hline 1-3 years & 2 & 12.5 & 5 & 6.3 \\
4-6 years & 4 & 25.0 & 8 & 10.0 \\
7-9 years & 2 & 12.5 & 10 & 12.5 \\
10-12 years & 3 & 18.8 & 6 & 7.5 \\
Over 12 years & 5 & 31.2 & 51 & 63.8 \\
Total & 16 & 100 & 80 & 100 \\
\hline
\end{tabular}

Source: Author 2012

According to the findings shown on Table, majority headteachers (31.2\%) had been in service for over 12 years while $25 \%$ had served for between $4-6$ years, $12.5 \%$ had served for between $7-9$ while $18.8 \%$ had served for $10-12$ years. This implies that most head teachers may be said to have adequate experience in school management. The findings further shows that $63.8 \%$ teachers had been in the teaching service for between $10-12$ years, while the minority $6.3 \%$ had served between 1-3 years The findings therefore reveal varied years of experience for head teachers and teacher in the teaching service.

Figure 5. Teachers Years of Service

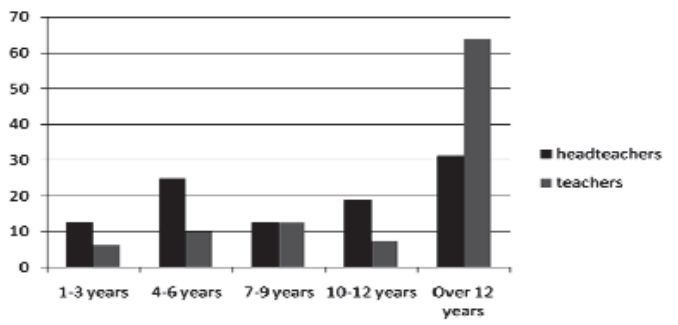

\subsection{Teachers and Headteachers training on SNE.}

The study sought to find out if the teachers and headteachers had undergone any training on SNE training. The results 
obtained are shown in the table below.

Table 7. Head teacher's and Teachers SNE training

Source: Author 2012

\begin{tabular}{ccccc}
\hline \multirow{2}{*}{ SNE training } & Yes & \multicolumn{3}{c}{ No } \\
& Frequency & $\%$ & Frequency & $\%$ \\
\hline Head Teacher & 4 & 25 & 12 & 75 \\
Teachers & 25 & 31.3 & 55 & 68.7 \\
Total & 29 & 30.2 & 67 & 69.8 \\
\hline
\end{tabular}

The data in the table above shows that majority $(75 \%)$ of the headteachers did not have SNE training as compared to $25 \%$ that had the training. the study further established that the majority (68.7) teachers had not undergone the SNE training while $31.3 \%$ had training on SNE. the results shown above show that the majority of headteachers and teachers had not had SNE training.

Figure 6. Head teacher's and Teachers SNE training
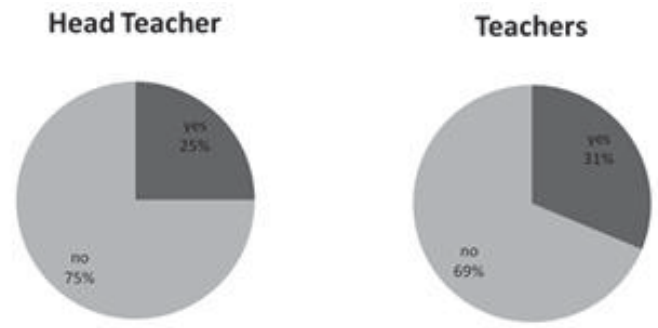

\subsection{Headteachers and Teachers Perceptions towards Implementation of Inclusive Education}

Headteachers and teachers are the key determinants of the success of the schools. Their perceptions on implementation of inclusive programmes in public primary schools are important for its successful implementation. Although the movement for inclusive education is part of a broad human rights agenda, many educators have serious reservations about supporting the widespread placement of pupils with special educational needs (Florien, 1998). The study aimed to establish the teachers perceptions on the implementation of the inclusive programmes and the results are shown in the table below.

Table 8. Head teachers and Teachers Perceptions towards Implementation of Inclusive Education

\begin{tabular}{|c|c|c|c|c|c|}
\hline Statement & SD & D & U & A & SA \\
\hline Pupils with special needs have the right to receive an education in mainstream classes & 8.8 & 8.8 & 1.3 & 40.3 & 41.3 \\
\hline Pupils with special needs will benefit from the inclusive program in regular classrooms & 6.3 & 1.3 & 7.5 & 26.3 & 58.8 \\
\hline Pupils with special needs need back up and support to learn in mainstream & 8.8 & 8.8 & 1.3 & 40 & 41.3 \\
\hline Pupils with special needs require special attention from teachers in classrooms & 6.3 & 2.5 & 0 & 16.3 & 75 \\
\hline Inclusive programmes are tedious to the regular classroom teachers & 8.8 & 7.5 & 5 & 52.5 & 26.3 \\
\hline Inclusion has negative effect on the regular students in the classroom & 22.5 & 30 & 7.5 & 28.8 & 11.3 \\
\hline Regular teachers are assisted by SNE trained teachers in teaching mainstream classrooms & 10.0 & 18.8 & 6.3 & 45 & 20 \\
\hline SNE pupils need special attention that cann & 10 & 12.5 & 6.3 & 43.8 & 27.5 \\
\hline nnot be included in mainstream classrooms & 3.8 & 8.8 & 2.5 & 46.3 & 38.8 \\
\hline trained teachers in mainstream & 7.5 & 27.5 & 10 & 33.8 & 21.2 \\
\hline 11. Pupils w & 11.3 & 11.3 & 3.8 & 40 & 33.8 \\
\hline 12. Pupils with special needs waste a lot of time for the non disabled pupils & 18.8 & 37.5 & 6.3 & 21.3 & 16.3 \\
\hline $\begin{array}{l}\text { 13. Government policy on education of individuals with disabilities is implicit and fails to provide } \\
\text { the mandated free education for them }\end{array}$ & 1.3 & 11.3 & 6.3 & 51.3 & 30 \\
\hline $\begin{array}{l}\text { 14. The current curriculum in the schools does not cater for leaning needs for some forms of } \\
\text { disabilities. }\end{array}$ & 6.3 & 7.5 & 12.5 & 41.3 & 32.5 \\
\hline
\end{tabular}


15. All the teachers should be trained on SNE needs in order to cater for inclusion.

$\begin{array}{lllll}7.5 & 3.8 & 6.3 & 40 & 42.5\end{array}$

16. Teachers attitude towards inclusion is the key factor to effective implementation of inclusion

$\begin{array}{lllll}6.3 & 1.3 & 6.3 & 42.5 & 43.8\end{array}$

\section{Source: Author 2012}

The data on the table above indicates that the majority (41.3\%) of the respondents strongly agreed that Pupils with special needs have the right to receive an education in mainstream classes as compared to (8.8\%) of the respondents who strongly disagreed. Although the movement for inclusive education is part of a broad human rights agenda, many educators have serious reservations about supporting the widespread placement of pupils with special educational needs (Florien, 1998). The study further established that the majority (58.8\%) of the respondents strongly agreed that Pupils with special needs will benefit from the inclusive program in regular classrooms as compared to (6.3\%) who strongly disagreed. This is in agreement by a report by Canadian Council on Learning (2009) that found that found that there was a favorable academic outcome for students with special education needs educated in inclusive settings.

The majority (41.3\%) of the respondents strongly agreed that Pupils with special needs need back up and support to learn in mainstream. the study further established that Pupils with special needs require special attention from teachers in classrooms as was indicated by the majority (75\%) who strongly agreed to the statement.

The study established that Inclusive programmes are tedious to the regular classroom teachers as was indicated by the majority (52.5\%) who were in agreement to this statement as opposed to (7.5\%) who disagreed. This is in agreement with Sebba \& Sachdev, (1997) who argued that In order to ensure education for all, including those children who have disabilities; it is increasingly asserted that modifying ordinary schools is the most effective way of doing this. The majority (30\%) of the respondents disagreed to the statement that Inclusion has negative effect on the regular students in the classroom as opposed to $11.3 \%$ who agreed.

The majority (45\%) of the respondents agreed that in their schools, Regular teachers are assisted by SNE trained teachers in teaching mainstream classrooms as opposed to (18\%) who were in disagreement. The study further established that some forms of special needs cannot be included in mainstream classrooms as so indicated by the majority (43.8\%) of the respondents who agreed to the statement, as opposed to (12.5\%) who disagreed with the statement. The argument is predicated on the premise that since each person is different, 'the way he learns will also differ' (Exley, 2003). This means that the teacher has to teach to satisfy the learning style of the different ranges of students in the class. The study further established that little help is provided by SNE trained teachers in mainstream, as agreed by the majority (33.8\%) of the respondents.

In regards to Pupils with SNE need to be put in integration classrooms, the majority (40\%) of the respondents agreed that they should be integrated, while only (11.3\%) disagreed. This is in agreement with Singal (2006) who concluded that many teachers believe that children who need academic moderation would be unable to cope with the level of academic demand in the mainstream schooling system. The study further established that the majority (37.5\%) disagreed to the Statement that Pupils with special needs waste a lot of time for the non disabled pupils while (21.3\%) agreed.

Majority (51.3\%) of the respondents agreed to the statement that Government policy on education of individuals with disabilities is implicit and fails to provide the mandated free education for them as opposed to $11.3 \%$ who disagreed. the study further established that The current curriculum in the schools does not cater for leaning needs for some forms of disabilities as indicated by the majority $(41.3 \%)$ of the teachers who Strongly agreed as opposed to $7.5 \%$ who disagreed.

The study established that the majority (42.5\%) of the respondents agreed that all the teachers should be trained on SNE needs in order to cater for inclusion. as opposed to $3.8 \%$ who disagreed. Research indicates that adequately trained professionals are required for students with special needs (Eleweke \& Rodda, 2002). Meng, (2008) argued that In addition, teachers" experience and their training significantly influence their attitudes. The study further established that the majority (43.8\%) of the respondents were of the opinion that Teachers attitude towards inclusion is the key factor to effective implementation of inclusion as opposed to (13\%) who disagreed.

\section{Challenges Faced in Implementation of Inclusion Programmes}

The second objective was to find out the perceptions of teachers and headteachers on the challenges facing in implementing inclusive education in Yatta Division. Despite international declarations regarding the implementation of inclusive education, there are challenges in both developed and developing countries, such as gaps between policies 
and practices, negative attitudes towards inclusion, and lack of sufficient funding (Charema, 2007).The study aimed at establishing the challenges the teachers and headteachers faced during the implementation of the inclusive education. The results obtained during the study are shown in the table 9 below.

Table 9. Challenges faced in implementation of inclusion programmes

\begin{tabular}{llcccc}
\hline Challenges to effective implementation of inclusive education & SD & D & U & A & SA \\
\hline 1. Lack of knowledge among teachers about special needs education & 3.8 & 5 & 6.3 & 32.5 & 52.5 \\
2. Lack of teaching and learning materials necessary for SNE & 2.5 & 1.3 & 0 & 32.5 & 63.8 \\
3. Low cognitive ability of some SNE students & 6.3 & 16.3 & 6.3 & 50 & 21.3 \\
4. Lack of access to relevant medical, psychological and other support & 6.3 & 5 & 1.3 & 47.5 & 40 \\
5. Lack of awareness of appropriate integration programs & 2.5 & 0 & 2.5 & 41.3 & 53.8 \\
6. Too much work which does not allow concentration on SNE issues & 2.5 & 2.5 & 11.3 & 33.8 & 50 \\
7. Lack of adequate government funding & 0 & 1.3 & 2.5 & 43.8 & 52.5 \\
8. Absence of suitable curriculum guidelines to cater for SNE & 1.3 & 3.8 & 3.8 & 47.5 & 43.8 \\
9. Research in special education has not received significant attention & 2.5 & 15 & 5 & 35 & 42.5 \\
10. Low perception \& negative attitude towards individuals with SNE & 0 & 12.5 & 7.5 & 38.8 & 41.3 \\
11. Low cultural value given to individuals with disability & 2.5 & 17.5 & 0 & 47.5 & 32.5 \\
12. Inadequate trained Special Needs Teachers & 1.3 & 8.8 & 1.3 & 43.8 & 45 \\
13. Inaccessible school facilities & 0 & 3.8 & 10 & 43.8 & 42.5 \\
14. Few institutions offering inclusive education & 1.3 & 6.3 & 2.5 & 40 & 50 \\
15. Very high teacher to student ratio makes individualized instruction & 7.5 & 3.8 & 8.8 & 17.5 & 62.5 \\
difficult & & & &
\end{tabular}

Source: Author 2012

The data in the table above indicates that the majority (52.5\%) of the respondents strongly agreed that Lack of knowledge among teachers about special needs education was a challenges in implementation of inclusive education, while only $5 \%$ of the respondents disagreed. the study further established that Lack of teaching and learning materials necessary for SNE was another challenge to inclusive education, as so revealed by the majority (63.8\%) who agreed, while $(1.3 \%)$ disagreed. This is in agreement with (Eleweke \& Rodda, 2002) who stated that Simple teaching resources that could normally be produced locally, such as maps, charts and other illustrative devices are not available in many educational institutions in developing countries.

The majority (50\%) of the respondents agreed that low cognitive ability of some SNE students was another challenge faced during implementation of inclusive education as opposed to $16.3 \%$ who disagreed. Stakes and Hornby (2000) suggest that teachers have to identify, possibly through assessment individual children's learning style in order to meet their needs .By learning style, it is meant the application of an individual's cognitive style to a learning situation the study further established that Lack of access to relevant medical, psychological and other support services was a challenge, as indicated by (47.5\%) of the respondents who agreed. $5 \%$ indicated that they disagreed to that statement.

Lack of awareness of appropriate integration programs was also highlighted as a challenge, as revealed by the majority (53.8\%) of the respondents who strongly agreed while $2.5 \%$ of the respondents disagreed. Another challenge highlighted was too much work which does not allow the teachers to concentration on SNE issues. This was indicated by the majority (50\%) of the respondents who strongly agreed, while $2.5 \%$ disagreed.

With regards to funding, the majority (52.5\%) strongly agreed that Lack of adequate government funding was a challenge to inclusion, as opposed to $1.3 \%$ who disagreed to the statement. The study further established that Absence of suitable curriculum guidelines to cater for SNE was also a challenge to implementation of inclusion as so revealed by the majority (47.5\%) who agreed to the statement while (3.8\%) disagreed. Singal (2006) found out that many teachers believe that children who need academic moderation would be unable to cope with the level of academic demand in the mainstream schooling system.

The study established that Research in special education has not received significant attention and this was a challenge, as indicated by the majority (42.5\%) who strongly agreed whereas (2.5\%) of the respondents strongly disagreed. Low perception \& negative attitude towards individuals with SNE was also highlighted as a challenge to effective inclusion as indicated by the majority (41.3\%) of the respondents who strongly agreed while (12.5\%) disagreed to this issue.

The majority (47.5\%) of the respondents agreed that Low cultural value given to individuals with disability while 
$(17.5 \%)$ disagreed. the study further established that Inadequate trained Special Needs Teachers was a challenge to implementation of inclusive education as revealed by $(43.8 \%)$ who agreed, while $(8.8 \%)$ of the respondents disagreed. Lack of school facilities to support inclusive education, was also revealed as a challenge to inclusion as indicated by the majority (43.8\%) of the respondents who agreed, whereas (3.8\%) of the respondents agreed. Eleweke and Rodda, (2002) noted that lack of facilities and teaching materials are major impediments to the implementation of inclusive education.

Another challenge highlighted was Very high teacher to student ratio which makes individualized instruction difficult. This was revealed by the majority (62.5\%) of the respondents who strongly agreed, as compared to (3.8\%) who disagreed. This goes in line with Gyimah ( 2006) who argued that inclusion is not possible especially where huge numbers of class sizes that some schools particularly in countries have to deal with.

Other challenges facing implementation of inclusive programmes in primary schools are: congested curriculum, community having the negative attitudes towards people with disabilities and few facilities to handle the numerous numbers of pupils with disabilities. From these findings, it is clear that the implementation of inclusive programmes in primary schools is faced with numerous challenges that are rooted in schools, personnel and the community.

\section{Strategies to Address the Challenges Faced in Implementation of Inclusion}

The third study objective sought to establish strategies to address the challenges facing the implementation of inclusive education. Data from the respondents is indicated in the table below.

Table 10. Strategies to Address the Challenges Faced in Implementation of Inclusion

\begin{tabular}{|c|c|c|c|c|c|}
\hline Suggested Solutions to challenges impending implementation of inclusive education & SD & D & $\mathrm{U}$ & A & SA \\
\hline 1. In-service training for Teachers. & 1.3 & 0 & 2.5 & 25 & 71.3 \\
\hline 2. Increase government funding towards special needs programmes & 0 & 1.3 & 1.3 & 17.5 & 80 \\
\hline 3. Increase the number of special schools and integration programmes & 0 & 1.3 & 1.3 & 38.8 & 58.8 \\
\hline 4. Increasing and improving the school facilities. & 0 & 1.3 & 2.5 & 36.3 & 60 \\
\hline 5. Development of a suitable curriculum to cater for SNE pupils & 0 & 5 & 0 & 28.8 & 66.3 \\
\hline 6. Constant evaluation of SNE policy on Inclusive education & 1.3 & 1.3 & 2.5 & 38.8 & 56.3 \\
\hline 7. Increase the budgetary allocation for specials schools in the free primary education & 0 & 0 & 1.3 & 30 & 68.8 \\
\hline
\end{tabular}

Few of SNE trained teachers in the schools was highlighted as a challenges to inclusion. This they said would be mitigated by in- service training of all the teachers in the primary schools to sensitize them on ways to cater for the pupils with special needs and schooling in the regular schools. This training should also enable the headteachers and teachers understand the different needs of the pupils with SNE in the inclusion programmes.

Financial constraint was identified as one of the challenges facing teachers and headteachers in implementation of inclusion in primary schools. The respondents suggested that Increase government funding towards special needs programmes could reduce the burden to the parents and also help in acquiring the materials and resources for the learners with SNE, to enable them fit and cope with the regular classrooms.

Increasing the number of special schools and integration programmes was also suggested as a strategy since some of the learners with certain disabilities cannot be included in the regular classrooms (eg Autistics) and therefore need to study in a special school or integration programmes since inclusion cannot be of much help. Absence of suitable curriculum guidelines to cater for SNE was highlighted as one of the challenges to integration. This they said could be mitigated by Development of a suitable curriculum to cater for SNE pupils while in the regular school.

Constant evaluation of SNE policy on Inclusive education is also a strategy to aid in improving inclusion. In this policy, they should constantly review the real-time status of the inclusion programmes in schools, find out the challenges and formulate the strategies to deal with the challenges highlighted. Another strategy to remedy the lack of learning and teaching resources for the intellectually challenged is to Increase the budgetary allocation for specials schools in the free primary education and award the increase per pupils with the special educational needs in each of the schools. Other suggested strategies to address the challenges facing inclusion include sensitization of the community on matters relating to disabilities, training of the headteachers and management of the schools on the various needs for the learners with disabilities so as to aid in management, and procuring more facilities for the learners with disabilities. 


\section{Conclusions}

Based on the findings discussed in the previous chapter, this study draws the conclusion that the headteachers and the teachers had a positive attitude towards the implementation of inclusion in primary schools, and that the SNE pupils required special attention during the learning in the regular classrooms. It can be concluded the SNE Trained teachers in the schools were not enough to handle the many Disabled pupils, most of the school managers and headteachers did not have knowledge on SNE requirements and that the facilities for teaching the SNE pupils were not adequate. It can also be concluded that the government was not effective enough in supporting the implementation of inclusion programmes in that its policy on education of individuals with disabilities is implicit and fails to provide the mandated free education for them. The current curriculum in the schools does not cater for leaning needs for some forms of disabilities.

\section{References}

Ainscow, M. (2005). Developing Inclusive Education Systems: What are the Levels for Change? Journal of Educational Change, 6(2), 109-124

Ainscow, M., \& Cesar, M. (2006). Inclusive education ten years after Salamanca: setting the agenda. European Journal of Psychology of Education, 21(3), 231-238.

Ainscow, M., Booth, T., Dyson, A., Farell, P., Frankham, J., Gallannaugh, F., Howes, A., \& Smith, R (1998).Improving schools:developing inclusion. London: Routledge.

Ali, M. M., Mustapha, R., \& Jelas, M. Z. (2006). An Empirical study on teachers perceptions towards inclusive education in Malaysia. International Journal of Special Education, 21(3), 36-44.

Bailey, J. (1998) Australia: Inclusion Through Categorisation?, From Them To Us: An International Study of Inclusion in Education (London, Routledge), 171-185.

Borg, W. \& Gall, M. (1989). Measures of validity of Research Instruments. London: Falmer.

Charema, J. (2007). From special schools to inclusive education: The way forward for developing countries south of the Sahara. The Journal of the International Association of Special Education, 8(1), 88-97.

Chinn, S. T. and Ashcroft, J. R. (1999) Mathematics for dyslexics: a teaching handbook. London: Whurr Publishers.

Croll, P., \& Moses, D., (2000). Ideologies and utopias: educational professionals views of inclusion. European Journal of Special Needs Education 15(1), 1-12.

Davis P, Florian L (2004) Teaching strategies and approaches for pupils with special educational needs: a scoping study. Nottingham: DfES.

Eleweke. J. \& Rodda. M. (2002). The Challenge of Enhancing Inclusive Education in Developing Countries. International Journal on Inclusive Education, 6(2), 113- 126.

Exley S (2003) The effectiveness of teaching strategies for students with dyslexia based on their preferred learning styles. British. J. Special Educ., 30(4): 213-219.

Florian L (2005) 'Inclusion', 'special needs' and the search for new understandings. Support for Learning, 20 (2): 96-98.

Florian L (2008) Special or inclusive education: future trends. British J. Special Educ., 35 (4), 202-208.

Foreman, P. (2005). Disability and inclusive: Concepts and principles. In P. Foreman (Ed.), Inclusion in action (pp. 2-32).Melbourne: Nelson Thomson.

Gyimah E.K (2006). Teachers' attitudes to inclusive education in Ghana, PhD Thesis submitted to the University of Leeds, United Kingdom

Hossain, D. (2004). Inclusive education: context Bangladesh. Journal of the Faculty of Arts, 6(1), 22-31.

Kibria, G. (2005). Inclusion education and the developing countries: The case of Bangladesh. The Journal of the International Association of Special Education, 6(1), 43-47.

Kristensen, K., Loican-Omagor, M. \& Onen, N. (2003). The inclusion of learners with barriers to learning and development into ordinary school settings: a challenge for Uganda. British Journal of Special Education, 30(4), 194-201.

Loreman, T., Forlin, C., \& Sharma, U. (2007). An International Comparison of Pre-service Teacher Attitudes towards Inclusive Education. Disability Studies Quarterly, 27(4), p5 5.Retrived on 7 June 2011 fromhttp://web.ebscohost.com. ezproxy. canterbury. ac.nz/ehost/detail?vid=3\&hid=106\&sid=4cc00acc-861e-4292-98b2

Martin, K. \& Acuna, C. (2002). SPSS for Institutional Researchers. Lewisburg, Pennsylvania: Bucknell University Press.

Meng, D. (2008). The attitudes of primary school teachers toward inclusive education in rural and urban China. Frontiers of Education in China, 3(4), 473-492.

Mitchell, D. (2008). What Really Works in Special and Inclusive Education: Using evidence based teaching strategies. London: Routledge.

Norwich B (1999) The connotation of special education labels for professionals in the field, Bri. J. Special Educ., 26 (4), 179-183.

Orodho J. A. (2002). Techniques of Writing Research Proposals and Reports in Education and Social Sciences. Nairobi: Masola Publishers

Peters, S. 2004. Addressing the Rights of Individuals with Disabilities in Relation to 'Education for All': Where do we stand? What do we 
know? What can we do?

Ross-Hill, R. (2009). Teacher Attitude towards inclusion practices and special needs students. Journal of Research in Special Educational Needs, 9(3), 188-198.

Sebba, J., \& Sachdev, D. (1997). What works in inclusive education? Ilford: Barnardos.

Singal, K. (2008). Inclusive Education in South Africa. International Journal of Special Education, 39 (2), 116-142.

Singal, N., Rouse, M. (2003). "We do inclusion":practitioner perspectives in some "Inclusive Schools in India, perspectives in education: Special issue, The 126 Inclusion/Exclusion Debate in South Africa and Developing Countries, 21(3), 85-98.

Singleton, R. A. (1993). Approaches to Social Research. New York. Oxford University Press.

Slavin, R. 1997. Including Inclusion in School Reform: Success for All and Roots and Wings. In Inclusion and School Reform: Transforming America's Schools, edited by D. K. Lipsky, Gartner, A. Baltimore: Paul Brookes Publishing Company.

Stakes R, Hornby G (2000) Meeting special needs in mainstream schools a practical guide for teachers (2nd ed.) London: David Fulton.

Stough, M. L. (2003). Special education and severe disabilities in Costa Rica: developing inclusion in a developing country. Research and Practice for Persons with Severe Disabilities, 28(1), 7-15.

The Daily e-Prothom Alo (2011). A survey from World Health Organization (WHO), Saturday, 11th June, p-11.

UNESCO (1994). Final report-World conference on special needs education: Access and quality. Paris: UNESCO.

UNESCO. (2009). Guidelines for Inclusion: Ensuring Access to Education for All. Paris: UNESCO.

Vygotsky, L. (1998) The Collected Works of L.S. Vygotsky. Vol.5. Child psychology. NY: Plenum Press.

Whyte, B. (2005). Collaborating with diverse cultures. In D. Fraser, R. Moltzen, \& K. Ryba, (Eds.), Learners with special education needs in Aotearoa New Zealand (3rd ed.) (pp. 117 127). Melbourne: Dunmore Press.

Wilczenski, F. L. (1992). Development of a scale to measure attitude toward inclusive education. Educational and Psychological Measurement, 55(2), 291-299. 
